\section{KONCEPT ODRŽANJA FIZIČKOG KAPITALA}

\section{O KONCEPTU ODRŽANJA KAPITALA}

Koncept održanja kapitala govori o načinu na koji entitet definiše kapital koji nastoji da održi. Ovaj koncept obezbeđuje vezu između koncepta kapitala i koncepta dobitka tako što pruža referentnu tačku za merenje dobitka. U opštem slučaju, entitet je održao svoj kapital ako je iznos kapitala na kraju perioda jednak iznosu kapitala na početku perioda. Svaki iznos preko onog koji je potreban za održanje kapitala sa početka perioda predstavlja dobitak. Drugim rečima, dobitkom se mogu smatrati samo prilivi sredstava koji premašuju iznose potrebne za održanje kapitala. (3, tačka 8.4; 2 tačka 4.60)

Pri sastavljanju finanijskih izveštaja, većina entiteta koristi jedan od sledeća dva koncepta kapitala:

(1) Koncept održanja finansijskog kapitala (kao neto imovine), ili

(2) Koncept održanja fizičkog kapitala.

Odabrani koncept ukazuje na cilj koji se želi postići pri utvrđivanju dobitka.

Prema konceptu održanja finansijskog kapitala, kapital označava investirani novac ili investiranu kupovnu moć, i sinonim je za neto imovinu preduzeća. Prema ovom konceptu, dobitak je ostvaren samo ako finansijski iznos neto imovine na kraju perioda premašuje finansijski iznos neto imovine na početku perioda, nakon isključivanja bilo kakvih raspodela vlasnicima ili doprinosa vlasnika $\mathrm{u}$ toku perioda. (3, tačka $8.1 ; 2$, tačka 4.57)

Prema konceptu održanja fizičkog kapitala, kapital označava proizvodnu sposobnost entiteta koja se izražava, na primer, brojem jedinica proizvoda za jedan dan. (3, tačka $8.1 ; 2$, tačka 4.57) Prema ovom konceptu, dobitak je ostvaren samo ako fizička proizvodna sposobnost (ili poslovna sposobnost) entiteta na kraju perioda premašuje njegovu fizič-
UDK: 330.142

005.934 .2

DOI: 
ku proizvodnu sposobnost na početku perioda, nakon isključivanja bilo kakvih raspodela vlasnicima ili doprinosa vlasnika u toku perioda. (3, tačka $8.3 ;$, tačka 4.59 )

Glavna razlika između ta dva koncepta je u postupku prema učincima promena cena sredstava i obaveza entiteta. Koncept fizičkog očuvanja kapitala zahteva usvajanje koncepta tekuće nabavne vrednosti ili tekuće cene koštanja (engl. 'current cost', često se prevodi kao 'tekući trošak', što nije uobičajeno u našoj računovodstvenoj terminologiji) kao osnove za merenje. (3, tačka 8.1; 2, tačka 4.61)

Koncept fizičkog ili poslovnog kapitala izražava sposobnost preduzeća da održi dati fizički nivo poslovanja. Nivo poslovanja može se označiti količinom robe i usluga određenog kvaliteta proizvedenom $\mathrm{u}$ određenom vremenskom periodu. Kada se kapital definiše u smislu fizičke proizvodne sposobnosti, sve promene cena koje utiču na sredstva i obaveze entiteta smatraju se promenom u merenju proizvodne sposobnosti preduzeća, i stoga usklađivanjem/korekcijama za potrebe održanja kapitala, a ne dobitkom. (3, tačka 8.8; 2, tačka 4.64) Ovaj koncept razmatra održanje kapitala iz perspektive samog preduzeća, pa stoga odražava entitetski koncept kapitala. $(5,4)$

Primer 1: Koncept održanja fizičkog kapitala (prema: 1, 2)

Scenario:

1. Entitet je osnovan 1 . januara $20 \mathrm{~K} 1$. godine sa 20.000 običnih akcija po ceni od 1 novčane jedinice - NJ.

2. Iz uplaćenih sredstava kupuje materijal u vrednosti od $20.000 \mathrm{NJ}$, koja se tokom godine prodaje za $25.000 \mathrm{NJ}$.

3. Tokom ovog perioda nije bilo drugih transakcija.

4. Na kraju godine nabavna cena materijala porasla je na $23.000 \mathrm{NJ}$.

Pitanje: Koliko iznosi ostvarena dobit u 20K1. godini?

Odgovor:

(1) Koristeći koncept fizičkog održanja kapitala, dobit za izveštajni period iznosi $2.000 \mathrm{NJ}(25.000-23.000 \mathrm{NJ})$.

(2) Ako se koristi koncept održanja finansijskog kapitala, dobit za godinu iznosi 5.000 NJ. Ako bi kompanija isplatila akcionarima $5.000 \mathrm{NJ}$ dobiti, ne bi mogla ponovo da kupi iste količinu materijala, jer je njegova nabavna vrednost porasla (u ovom slučaju, dobit je razlika između prodajne i nabavne vrednosti materijala).

(3) Da bi operativna sposobnost entiteta ostala ista, prodajna vrednost materijala trebalo bi da iznosi $28.000 \mathrm{NJ}$. 


\section{Primer 2: Koncept održanja fizičkog kapitala (prema: 5, 5)}

Tokom 20K1. godine, kompanija koja se isključivo finansira sopstvenim kapitalom nabavila je opremu po ceni od 40.000 novčanih jedinica (NJ). Na dan 31.12.20K1. godine tekuća nabavna vrednost ili tekuća cena koštanja te opreme porasla je na $60.000 \mathrm{NJ}$. Na dan 31.12.20K2. godine, ova oprema je prodata za 100.000 NJ. U momentu prodaje, tekuća nabavna vrednost ili tekuća cena koštanja te opreme iznosila je 65.000 NJ.

Primenom uobičajenog koncepta istorijske tj. nabavne vrednosti odmeravanja imovine i rezultata, dobitak na transakciji $\mathrm{u}$ momentu prodaje opreme na kraju 20K2. godine iznosio bi 60.000 NJ (100.000 NJ - 40.000 NJ).

Primenom koncepta fizičkog održanja kapitala, ostvareni dobitak segmentirao bi se u nekoliko perioda.

1. Prvi segment bilansiranja dobitka ostvario bi se na dan 31.12.20K1. godine. U ovom momentu preduzeće bi ostvarilo nerealizovani dobitak od 20.000 NJ, računat kao razlika između tekuće nabavne vrednosti opreme na taj dan od $60.000 \mathrm{NJ}$ i istorijske nabavne vrednosti opreme od $40.000 \mathrm{NJ}$.

2. Drugi segment bilansiranja dobitka ostvario bi se na dan $31.12 .20 \mathrm{~K} 2$. godine. U ovom momentu preduzeće bi ostvarilo nerealizovani dobitak od 5.000 NJ, računat kao razlika između tekuće nabavne vrednosti na dan 31.12.20K2. godine od 65.000 NJ i nabavne vrednosti od $60.000 \mathrm{NJ}$ na dan $31.12 .20 \mathrm{~K} 1$. godine, koja je već iskazana $\mathrm{u}$ bilansu.

3. Treći segment bilansiranja dobitka ostvario bi se iz aktivnosti prodaje, meren na dan prodaje, kao razlika između prodajne cene od 100.000 NJ i iskazane nabavne vrednosti na dan zadnjeg bilansa od 65.000 dinara, tj. $u$ iznosu od $35.000 \mathrm{NJ}$.

Ilustracija 1: Uporedni predgled priznavanja dobitka primenom koncepta finansijskog i fizičkog održanja kapitala

(Svi iznosi su u NJ)

\begin{tabular}{|c|c|c|c|c|}
\hline Transakcija & $\begin{array}{l}\text { Vrednost } \\
\text { transakcije }\end{array}$ & Vrsta dobitka & $\begin{array}{c}\text { Dobitak prema } \\
\text { konceptu održanja } \\
\text { finansijskog kapitala }\end{array}$ & $\begin{array}{l}\text { Dobitak prema } \\
\text { konceptu održanja } \\
\text { fizičkog kapitala }\end{array}$ \\
\hline $\begin{array}{l}\text { Tokom } 20 \mathrm{~K} 1 \text { - nabavna vrednost } \\
\text { opreme na dan kupovine }\end{array}$ & 40.000 & & & \\
\hline $\begin{array}{l}\text { 31.12.20K1. nabavna vrednost iste } \\
\text { takve opreme na dan } 31.12 .20 \mathrm{~K} 1 \text {. }\end{array}$ & 60.000 & Zadržani dobitak & 20.000 & - \\
\hline $\begin{array}{l}\text { 31.12.20K2. nabavna vrednost iste } \\
\text { takve opreme na dan } 31.12 .20 \mathrm{~K} 2 \text {. }\end{array}$ & 65.000 & Zadržani dobitak & 5.000 & - \\
\hline $\begin{array}{l}\text { 31.12.20K2. prodajna vrednost } \\
\text { opreme }\end{array}$ & 100.000 & Poslovni dobitak & 35.000 & 60.000 \\
\hline Ukupan dobitak & & & 60.000 & 60.000 \\
\hline
\end{tabular}


Ovaj primer jasno pokazuje da se razlika između dva koncepta odnosi samo na dinamiku priznavanja dobitka, jer je ukupan dobitak isti u oba slučaja i iznosi $60.000 \mathrm{NJ}$.

Zadržani dobitak naziva se "nerealizovanim", sve do momenta prodaje, kada postaje "realizovan“. Zadržani dobitak ne smatra se profitom, već se iskazuje na posebnom računu u okviru kapitala kao „rezerva za održanje kapitala“. Smisao ove rezerve je u tome da ukaže na promene vrednosti tekuće nabavne vrednosti ili tekuće cene koštanja sredstava (u ovom slučaju opreme).

Prednost koncepta fizičkog održanja kapitala je u tome što pruža detaljnije informacije za potrebe raspodele dobitka na deo zadržane dobiti i na deo za isplatu vlasnicima od koncepta finansijskog održanja kapitala, kao i kvalitetnije informacije za poređenje sa drugim preduzećima. Pod pretpostavkom da je ceo iznos poslovnog dobitka podeljen vlasnicima u obliku dividendi, sažeti bilansi stanja preduzeća po svakom od navedenih koncepata održanja kapitala na dan 31.12.20K2. godine bio bi ovakav:

Ilustracija 2: Bilans stanja na dan 31.12.20K2. godine primenom koncepta održanja finansijskog kapitala

(Svi iznosi su u NJ)

\section{Bilans stanja}

(Koncept održanja finansijskog kapitala)

\begin{tabular}{|c|c|c|c|}
\hline \multicolumn{2}{|l|}{ Aktiva } & \multicolumn{2}{|l|}{ Pasiva } \\
\hline $\begin{array}{l}\text { Gotovina (100.000 n.j. - } 60.000 \text { n.j. } \\
\text { isplaćeno na ime dividendi) }\end{array}$ & 40.000 & Kapital & 40.000 \\
\hline Ukupno & 40.000 & Ukupno & 40.000 \\
\hline
\end{tabular}

Napomena: Celokupan iznos dobiti od 60.000 NJ isplaćen je vlasnicima na ime dividendi (prodajna vrednost od $100.000 \mathrm{NJ}$ minus $40.000 \mathrm{NJ}$ nabavna vrednost opreme). Preostali iznos gotovine od $40.000 \mathrm{NJ}$ zadržan je na računu entiteta.

Ilustracija 3: Bilans stanja na dan 31.12.20K2. godine primenom koncepta održanja fizičkog kapitala

(Svi iznosi su u NJ)

Bilans stanja
(Koncept održanja fizičkog kapitala)

\begin{tabular}{|c|c|c|c|}
\hline \multicolumn{2}{|l|}{ Aktiva } & \multicolumn{2}{|l|}{ Pasiva } \\
\hline $\begin{array}{l}\text { Gotovina ( } 100.000 \text { n.j. }-35.000 \text { n.j. } \\
\text { isplaćeno na ime dividendi) }\end{array}$ & 65.000 & Kapital & 40.000 \\
\hline & - & $\begin{array}{l}\text { Rezerve } \\
\text { za } \\
\text { fizičko } \\
\text { održanje } \\
\text { kapitala }\end{array}$ & 25.000 \\
\hline Ukupno & 65.000 & Ukupno & 65.000 \\
\hline
\end{tabular}


Napomena: Celokupan iznos dobiti od 35.000 NJ isplaćen je vlasnicima na ime dividendi (prodajna vrednost od 100.000 NJ minus $65.000 \mathrm{NJ}$, kolika je nabavna vrednost ili cena koštanja iste takve opreme na dan bilansa). Preostali iznos gotovine od $65.000 \mathrm{NJ}$ zadržan je na računu entiteta.

\section{ŠTA OVI KONCEPTI ZNAČE U STVARNOM ŽIVOTU?}

I koncept održanja finansijskog kapitala i koncept održanja fizičkog kapitala pružaju korisne informacije, ali za različite namene.

Investitori radije koriste koncept održanja finansijskog kapitala, jer su usredsređeni na povećanje i maksimiziranje prinosa na uložena sredstva.

Rukovodstvo i uprava skloniji su korišćenju koncepta održanja fizičkog kapitala jer im on omogućuje da procene sposobnost entiteta da održi svoj poslovni kapacitet. Ovo je posebno važno za proizvodna preduzeća, tamo gde menadžment treba da obezbedi nastavak proizvodnje iste količine proizvoda ili usluga.

\section{LITERATURA}

1. Chartered Education (2015) The 2 Concepts of Capital under IFRS. Dostupno na: https://www.charterededucation.com/ifrs/the-2-concepts-of-capital-under-ifrs/\#: :text=A\%20physical\%20concept\%20 of $\% 20$ capital\%20is\%20one\%20where\%20the\%20capital,on\%20its\%20units\%20of\%20output.\&text=The\%20main\%20concern\%20 of\%20users,operating\%20capability\%20of\%20the\%20entity. Preuzeto: 20.05.2021.

2. IASB (2010) Konceptualni okvir za finansijsko izveštavanje, Ministarstvo finansija Republike Srbije. Dostupno na: https://www. mfin.gov.rs//upload/media/XWGjnu_6015e1b7a94b3.pdf. Preuzeto 20.05.2021.

3. IASB (2018) Conceptual Framework for Financial Reporting. London, UK: International Accounting Standards Board.

4. Lewis, Jared (NP) What Is Physical Capital Maintenance?, Chron. https://smallbusiness.chron.com/physical-capital-maintenance-38589.html. Preuzeto 20.05.2021.

5. Nandwe, Manukriti (NP) Top 3 Concepts of Capital Maintenance in an Enterprise. Dostupno na: https://www.accountingnotes.net/financial-statement/income-concepts/top-3-concepts-of-capital-maintenance-in-an-enterprise/5315. Preuzeto: 13.04.2021. 